\title{
At-issueness in direct quotation: the case of Mayan quotatives*
}

\author{
Scott AnderBois \\ Brown University
}

\begin{abstract}
In addition to lexical verbs of saying, many languages have more grammaticized means for reporting the speech of others. This paper presents the first detailed formal account of one such device: quotative morphemes in Mayan languages, with a focus on Yucatec Maya ki(j). When mentioned in previous literature, quotatives have either been regarded as a special kind of verb of saying or reportative evidential. I argue that quotatives have important differences (and some similarities) with both verbs of saying and reportatives. To capture these properties, I propose a 'scoreboard' account where quotative $k i(j)$ signals that the co-occurring quotative material demonstrates a move in an in-narrative scoreboard.
\end{abstract}

Keywords: Illocutionary Mood, Narrative, Parentheticals, Quotation, Reported Speech

\section{Introduction}

All languages presumably have lexical verbs of saying (henceforth SAY) roughly analogous to English say, ask, and tell that can used to report the speech of others, usually in combination with linguistic material that characterizes in some way the form and/or content of what was said/asked/told. Alongside these lexical means of reporting speech, many languages also have reportative evidentials - functional morphemes such as Yucatec Maya (YM) bin REP in (1). ${ }^{1}$

* First and foremost, my heartfelt thanks to the native speaker language consultants who shared their language with me and whose hard work and careful thinking helped produce many important insights: Rosa Isela Canche Cen, Margarita Hau Hau, Norma Patricia Kuyoc Kuyoc, and Luis Petul. Thanks also to Pranav Anand, Diti Bhadra, Miguel Oscar Chan Dzul, Masha Esipova, Donka Farkas, Polly Jacobson, José Alfredo López Jiménez, Irma Yolanda Pomol Cahum, Wilson Silva, and the audiences/reviewers at FAMLI 5, UConn, McGill, Topics at the Semantics-Pragmatics Interface at UC Santa Cruz, and SALT 29 for helpful comments and ideas about this material.

1 The following abbreviations are used for glosses: CTQ: contrastive topic question, DAT: dative, DEF: definite article, DIST: distal, IMPER: imperative, IPFV: imperfective aspect, INTERR: interrogative, MIR: mirative, NEG: negation, NEG.CL: negative/extrafocal clitic, PFV: perfective aspect, PL: plural, PREP: preposition, PROG: progressive aspect, PROX: proximal deixis, REL: relational noun suffix, SUBJ: subjunctive mood, TOP: topic marker, For agreement morphology, I follow the terminological tradition among Mayanists, referring to Set $\mathrm{A}(\approx$ Ergative/Nominative $)$ and Set $\mathrm{B}(\approx$ Absolutive/Accusative) markers, e.g. A3 = 3rd person Ergative/Nominative.

(C)2019 AnderBois 
(1) Context: I am talking with you when my friend Alfredo calls on the phone. I tell you after the call:

Le péek'=o' t-u jant-aj bin paastel

DEF dog=DIST PFV-A3 eat-SS REP cake

'The dog ate birthday cake, I heard (from Alfredo telling me)'

In this paper, we present the first detailed formal analysis of a third type of reported speech device: quotatives like Yucatec Maya $k i(j)$ QUOT, in (2). ${ }^{2}$

$$
\begin{aligned}
& \text { Le péek'=o' t-u jant-aj paastel — } \mathbf{k i j} \\
& \text { DEF dog=DIST PFV-A3 eat-SS cake QUOT.B3 } \\
& \text { " "The dog ate birthday cake" — he says.' }
\end{aligned}
$$

While there is ample variation within both reportatives and verbs of saying, there are also some more or less consistent properties distinguishing the two. We return to examine these properties in more detail below, but summarizing briefly based on recent literature on reportatives (e.g., Faller 2002, Matthewson, Davis \& Rullmann 2007, Murray 2010, 2014, 2017, AnderBois 2014, 2017), we can draw the following conclusions:

\section{(3) Properties of Reportatives and Verbs of Saying:}

$\begin{array}{lll} & \text { REP } & \text { Verbs of Saying } \\ \text { Indirect speech use? } & \text { Yes } & \text { Yes } \\ \text { Direct speech use? } & \text { No } & \text { Yes } \\ \text { Original speech event not at-issue } & \text { Often conventional } & \text { Pragmatic } \\ \text { Interaction with sentence type } & \text { Variable, complex } & \text { Narrow scope } \\ \text { Details of original speech event } & \text { Implicit } & \text { Explicit }\end{array}$

On the infrequent occasions where they have been discussed, QUOT have generally been considered a special case of SAY (e.g. Bary \& Maier 2018) or REP (e.g. Krawczyk 2012, Blain \& Déchaine 2007). In contrast, we argue here that Mayan QUOT differ substantially from both REP and SAY in the properties in (3) and therefore ought to be considered a distinct phenomenon from both. Mayan QUOT always involve direct speech reports, unlike REP, but have conventional not-at-issueness, unlike SAY. In contrast with both REP and SAY, they always take wide scope relative

2 The name 'quotative' has been used in previous literature to several distinct phenonema. First, the term has sometimes been used, especially in older literature, to refer to what we are calling here reportative evidentials. Second, the term has been applied to complementizers which introduce direct quotation or some kind and/or complements which blur the line between direct and indirect speech in some way, such as Japanese -to/-tte (e.g. Maier 2009), A'ingae khen, Kannada anta (Jayaseelan \& Amritavalli 2017). Some of these complementizers may also exhibit standalone 'insubordination'-like uses where they occur in the absence of a lexical SAY. We set aside this sort of quotative here as it is a fundamentally different phenomenon. 
At-issueness in direct quotation: the case of Mayan quotatives

to illocutionary mood, and allow for a conventional encoding of certain aspects of the original speech event, but not others. To capture these properties, we develop a formal analysis within a scoreboard model of discourse following AnderBois 2014, 2017, Farkas \& Bruce 2010.

$\S 2$ summarizes the major formal properties of QUOT and REP in Mayan languages; $\$ 3$ argues that QUOT involve direct quotation with all indexicals shifting, whereas REP do not; $\$ 4$ argues that despite involving direct quotation, QUOT conventionally mark facts about the original speech event as not-at-issue content; $\$ 5$ contrasts the illocutionary effects of REP and QUOT in non-declarative sentences; §6 develops a formal analysis of QUOT building on AnderBois $(2014,2017)$ 's scoreboard analysis of REP; and $\$ 7$ concludes.

\section{Formal properties of Mayan quotatives and reportatives}

In this section, we briefly review the formal properties of QUOT, focusing on Yucatec Maya $k i(j)$, and comparing it with bin REP. We refer the reader to AnderBois 2019 for more extensive description (see also Lucy (1993), Hull (2003), López Jiménez (2010), Curiel (2016) for description of individual languagues). Outside of the Eastern subfamily (where the empirical situation is somewhat murkier), most Mayan languages have QUOT and REP:

\begin{tabular}{lll}
\multicolumn{3}{c}{ Tentative list of REP and QUOT in (non-Eastern) Mas M } \\
Language/Branch & REPORTATIVE & QUOTATIVE \\
\hline Wastek & $k w a^{\prime}$ & $? ?$ \\
Yucatecan & $b i n$ & $k i(j)$ \\
Yokot'an & $a^{\prime} i$ ' & $? ?$ \\
Ch'ol & $b i$ & $c h e^{\prime}$ \\
Ch'orti' & $a y i$ & $c h e$ \\
Tseltalan & $l a$ & $x i$ \\
Tojolab'al & $b^{\prime} i$ & $c h i$ \\
Chuj & $a b^{\prime}$ & $c h i$ \\
Q'anjob'al & $(h) a b^{\prime}$ & $x i$ \\
Akatek & $a b^{\prime}$ & $x h i$ \\
Popti' & $a b^{\prime} / o b^{\prime}$ & $x i$ \\
Mocho' & $a b^{\prime} / a b i^{\prime} / b i$ & $k i$
\end{tabular}

Despite the substantial differences we will show below, the line between them in previous literature has has often been quite blurry. One reason for this is that many authors have focused on perlocutionary effects shared by the two forms (e.g. 'speaker distancing') but in contrast to sentences with no reported speech elements. Second, REP and QUOT can frequently co-occur not only with one another but also with 
SAY. As illustrated in (5), such sentences typically receive a 'reportative concord' interpretation, i.e. they are compatible with scenarios with only a single original speech event rather than requiring a sequence of such events.

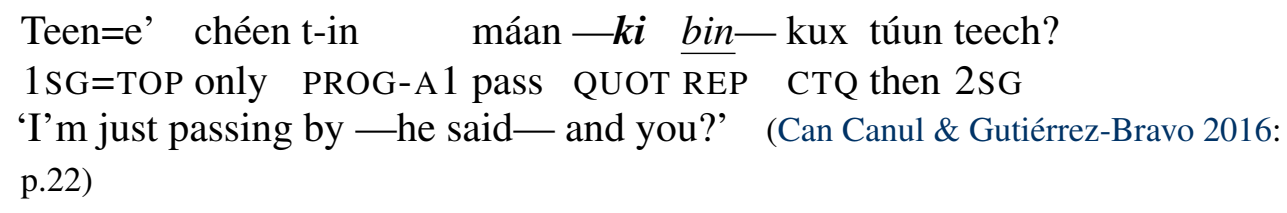

In terms of their distributional properties, the position of both REP and QUOT is prosodically determined. REP in Mayan languages are prosodically integrated and are typically second position clitics (e.g. Curiel 2016 for Tojolab'al =b'i). Our main focus here, YM bin, is most typically second position, but exhibits quite a bit more flexibility, being possible at any prosodic word boundary. ${ }^{3}$ In contrast, QUOT are prosodically unintegrated, constituting - along with their arguments - their own parenthetical intonational phrase either medially, (7), or more commonly, finally, (8).

(6) $\quad[\mathrm{T}-\mathrm{u} \text { jantaj } \underline{\text { bin }} \text { paanucho le máak=o' }]_{\text {Int } P}$ PFV-A3 eat REP panucho DEF person=DIST 'That guy ate panuchos, I heard.'

(7) $[\mathrm{T}-\mathrm{u} \text { jantaj paanucho le máak=0' }]_{\text {Int } P}[k i j \text { teen Margarita }]_{\text {Int } P}$ PFV-A3 eat panucho DEF person=DIST QUOT DAT.1SG Margarita ' "That guy ate panuchos" - Margarita told me.'

[T-u jantaj $]_{\text {Int } P}[\boldsymbol{k i j} \text { teen Margarita }]_{\text {Int } P}[\text { paanuchole máak=o' }]_{\text {Int } P}$ PFV-A3 eat QUOT DAT.1SG Margarita panucho DEF person=DIST ، "That guy" - Margarita told me - "ate panuchos". '

Although REP are often described as markers of hearsay, REP are equally felicitous in situations where the original speaker's identity is clear in context, often to the point of being essentially anaphoric, (9). Despite this, REP do not license any overt expression of the original speaker (see AnderBois 2017 for YM bin), nor of other aspects of the original speech event such as the addressee, spatiotemporal properties, manner, etc.

(9) Context: I am talking with you when my friend Alfredo calls on the phone. I tell you after the call:

Le péek'=o' t-u jantaj bin paastel DEF dog=DIST PFV-A3 eat REP cake 'The dog ate birthday cake, he (Alfredo says)'

3 For example, in (6), bin could also be realized following paanucho or máak (but preceding the clausal clitic $=o^{\prime}$ DIST) . 
At-issueness in direct quotation: the case of Mayan quotatives

In contrast, $k i(j)$ QUOT inflects to encode the original speaker being quoted via set B/Absolutive agreement, as seen in the paradigm in (10), and allows for an overt nominal expression as well (e.g. Margarita in (7)). Additionally, the addressee can be overtly expressed as a dative argument (e.g. teen DAT.1SG in (7)). While this differs plainly from REP, it also differs in several ways from SAY. First, the agreement pattern with QUOT is unlike that of SAY. Second, whereas finite verbs in YM ordinarily require aspect/modal marking, QUOT do not allow for this possibility. Finally, negation and other sorts of adverbial modifiers found with SAY are not possible with QUOT. In sum, QUOT differ from both REP and SAY in allowing for limited aspects original speech event to be encoded.

Yucatec Maya Quotative Paradigm:

$\begin{array}{llllll}\text { k-en } & \text { k-ech } & \text { ki(j) } & \text { k-o'on } & \text { k-e'ex } & \text { ki(j)-o'ob } \\ \text { QUOT-B1SG } & \text { QUOT-B2SG } & \text { QUOT.B3SG } & \text { QUOT-B1PL } & \text { QUOT-B2PL } & \text { QUOT-B3PL } \\ \text { 'I said' } & \text { 'you said' } & \text { 's/he said' } & \text { 'we said' } & \text { 'you all said' } & \text { 'they said' }\end{array}$

\section{Quotatives involve direct quotation}

The most fundamental - and arguably definitional - property of QUOT is that they involve a canonical direct speech report, whereas REP pattern with indirect speech. To see this, consider the original speech event in (11). Having been the addressee of (11), I could then subsequently report this original speech event using either REP or QUOT, as in (12). If I choose to do so with QUOT, as in (12a), it is the original speaker's words which I must use, with indexical expressions interpreted relative to the original speaker, María. In (12a), these are the first person agreement marker in A1SG, as well as the mirative particle bakáan MIR, which AnderBois (2018) shows to be uniformly speaker-oriented. Conversely, with REP in (12b), it is the meaning of the original speaker that must be maintained, but indexical expressions like pronouns and particles are interpreted relative to the speaker of (12b) rather than María. We see the same pattern for all other deictic expressions including vocatives (e.g. (25a)), second and third person pronouns, spatial and temporal ${ }^{5}$ indexicals, etc.

(11) Context: María is studying and sees storm clouds on the horizon and realizes she needs to stop studying in order to get home before the rains come. She

4 Given its absence in 1 st and 2 nd person forms, the $i(j)$ in the 3 rd person singular form at first blush appears to be the perfective/subjunctive status suffix -ij. While a likely diachronic source for it, two facts argue against this synchronically. First, the 3rd person plural form is kijo'ob, whereas the status suffix $-i j$ is blocked by the presence of $-o$ ' $o b$ B $3 \mathrm{SG}$ in all other uses. Second, the 3rd person singular quotative is $k i(j)$ rather than $k$ even when an overt subject DP or dative addressee DP occurs, as in (7-8), whereas the status suffix - $i j$ only surfaces in intonational phrase final position.

5 YM is a tenseless language, Bohnemeyer (2002), so we cannot look at tense itself. 
says:

K'abéet bakáan in ts'o'oksik in xook

NECES MIR A1 finish A1 study

'Oh, I need to finish studying.'

(12) Context: María said (11) to me and I tell you later:

a. K'abéet bakáan in ts'o'oksik in xook - $k i j$ teen

NECES MIR A1 finish A1 study QUOT DAT.1SG

" "I need to finish studying" - she told me.'

b. K'abéet bin (\#bakáan) u ts'o'oksik u xook.

NECES REP MIR A3 finish A3 study

'She needs to finish her studies, she says.'

Beyond this, we see that substitution of coreferring expressions is possible with REP, (14b), but not with QUOT, (14a). That is to say, QUOT involve verbatim quotation, while REP do not. As discussed by Maier (t.a.) for mixed quotation, the relevant notion of "verbatim" is itself vague, with the degree of precision required to be considered verbatim being context-dependent.

(13) Context: A mother tells you that her son is afraid of being bit by a dog:

In iijo=e' sajak káa chi'ibik tumeen le péek'=o'

A1 son=TOP afraid for bite.PASS.SUBJ by DEF dog=DIST

'My son is afraid that the dog will bite him.'

(14) Context: After talking to the mother, you tell your friend about the original speech event in (13):
a. \# Le champaal=o' sajak
káa chi'ibik
tumeen le péek'=o'

DEF boy=DIST afraid

for bite.PASS.SUBJ by

DEF dog=DIST

$-k i j$

QUOT

Intended: 'The boy is afraid that the dog will bite him (she says).'

b. Le champaal=o' sajak bin káa chi'ibik tumeen le péek'=o'

DEF boy=DIST afraid REP for bite.PASS.SUBJ by DEF dog=DIST

'The boy is afraid that the dog will bite him (she says).'

In sum, the material which co-occurs with QUOT shows all ${ }^{6}$ of the signs of direct quotation, being subject to a verbatim requirement, including all indexical

6 N.B. some of the additional tests used in recent literature to distinguish direct quotation from other forms of indexical shift such as NPI-licensing and wh-extraction cannot be applied to QUOT since QUOT themselves cannot be negated, questioned, etc. The impossibility of wh-extraction and NPI licensing across QUOT therefore does not tell us anything further in this case. 
At-issueness in direct quotation: the case of Mayan quotatives

expressions. REP, on the other hand, show no signs of this, with indexical expressions of all sorts interpreted relative to the current speaker rather than the speaker of the original speech event.

\section{Reported speech event conventionally not at-issue in quotatives}

Thus far, we have seen that YM $k i(j)$ QUOT involve verbatim direct quotation, in stark contrast to REP, which involve indirect speech only. While this already differs from SAY in that the QUOT only occur with direct speech reports, it nonetheless is similar to one use of SAY. In this section, we show that QUOT are distinct from SAY - and like REP - in another respect: they conventionally encode the not-at-issue status of the original speech event itself. Coupled with their unique prosodic and formal properties laid out in $\S 2$, we conclude that QUOT differ in substantial ways from both SAY and REP.

Simple past uses of SAY and REP both entail the existence of an original speech event, i.e. the prior speech event the speaker reports on using the utterance containing the SAY or REP. Although both entail the existence of such an event, this content typically has a different status in the two cases. For REP in many ${ }^{7}$ languages, the existence of the original speech event with particular properties cannot be the main point according to various properties, i.e. is what has come to be called "not-atissue" content. In contrast, SAY at least have the potential for the original speech event to serve as at-issue content, although a suitable context can render this content not-at-issue, as has been discussed by various recent works (e.g. Simons 2007, Hunter 2016, AnderBois 2016).

Recent literature on reportatives and evidentials generally (e.g. Faller 2002, 2006, Matthewson et al. 2007, Murray 2010, 2014, 2017) presents several diagnostics for the not-at-issue status. Applying these to YM, we show that bin REP and $k i(j)$ QUOT both have the existence of the original speech event along with details of it as not-at-issue content.

The first diagnostic for at-issueness concerns QUD-sensitivity: is a given sentence which entails the existence of a prior speech event felicitous as a response to QUDs $^{8}$ about who said what to whom? If a sentence is felicitous in such a context,

7 There are a few cases of REP which - while presumably being used primarily in this way - have been argued to not conventionally encode that the fact of the original speech event is not-at-issue content: Faller 2006 for German sollen, Matthewson et al. 2007 for St'átimcets ku7, Korta \& Zubeldia 2014 for Basque omen, Kierstead (2015) for Tagalog daw. Regardless, the cross-linguistic overall nonetheless presents a clear contrast with verbs of saying, which, to my knowledge, never conventionalize at-issueness in this way.

8 N.B. this is hard to test with simple Question-Answer pairs since even matrix sentences with no reported speech element of any kind are often felicitous in response to relevant QUDs. For example, the following English dialogue is felicitous: 
then the claims about the original speech event are at-issue content (though as noted above, the same form could be used in a 'pragmatically parenthetical' way in a different context). If infelicitous, then the claims about the original speech event are not-at-issue.

As we see in (15), the original speech event with YM bin REP is not-at-issue content according to this diagnostic:
José bin óokolt
le wakax $=$ o'.
José REP steal.AGENTFocus DEF cow=DisT
'José stole the cow they say.'

a. $\checkmark$ Scope-at-issue QUD: You are a detective trying to figure out who stole the cow.

b. X Report-at-issue QUD: You already know who stole what animals, but are trying to figure out which crimes the speaker has heard about to study how gossip spreads.

Turning to QUOT, we find the same pattern. Although the sentence in (16) entails the existence of a prior speech event with the words Yaan wáay tu kajil espita, the sentence is infelicitous as a response to QUDs about who said what, including more specific QUDs such as 'What did Luis say?'. We return below to examine the contexts in which such a sentence is felicitous, but note that they are ones where the quoted words themselves are appropriate in some salient context.

Yaan wáay t-u kaj-il espita $-\boldsymbol{k i}$ teen

EXIST ghost PREP-A3 town-REL espita-QUOT.B3SG DAT.1SG

" "There's ghosts in Espita" -he tells me.'

a. $\checkmark$ Scope-at-issue QUD: A character in a narrative is trying to find out if there are ghosts in Espita.

b. X Report-at-issue QUD: You want to know what Luis said about ghosts is his town.

A second diagnostic used in recent literature on evidentials concerns whether or not unmarked responses analogous to English 'yes' and 'no' can be used to respond

(i) Q: "What did you hear?"

(ii) A: "(That) John is in jail."

We assume that the A response in such a case is a fragment answer, felicitous not due to A's response addressing the QUD, but rather because A's response receives an elliptical interpretation 'I heard that John is in jail'. Additionally, in many such cases, the SAY in the question itself may be interpreted as pragmatically parenthetical such that the QUD in the discourse does not concern who said what. 
At-issueness in direct quotation: the case of Mayan quotatives

to the existence/properties of the original speech event. In $\S 5$, we consider sentence types other than declaratives, which in some sense can be thought of as generalizing this diagnostic insofar as interrogatives and imperatives license/require different sorts of responses. For reportative bin in YM, such responses can felicitiously used only to target the content being reported, but not the facts of the original speech act itself:

(17) Context: I was talking with my friend Juan on the phone and am talking to another friend now.

Jach k'asa' an $\underline{\text { bin }}$ Oscar

very bad REP Oscar

'Oscar is very bad (Juan says).'

a. $\checkmark$ Ma' jaaj=i' (leti'=e' ma' bey=o')

NEG true $=$ NEG.CL he $=$ TOP NEG like.that=DIST

'That's not true (he's not like that)'

b. $x$ Ma' jaaj=i' (mix máak t-u ya'alaj bey=o')

NEG true=NEG.CL no person PFV-A3 say like.that=DIST

Intended: 'That's not true (no one said that).'

Once again, $k i(j)$ QUOT patterns similarly in that unmarked responses are infelicitous as a means of confirming or denying the existence/properties of the original speech event. One important difference to note here is that such responses are simply infelicitous in response to QUOT, rather than receiving a different interpretation relating to the original speech event (indeed the actual addressee of a sentence with QUOT generally does not give any explicit response). We expand on this difference in more detail below. The basic intuition is that a speaker who utters a sentence like (17) with a reportative does make an assertion of some kind using the content of the original speech event. In contrast, a speaker using a QUOT as in (18a) performs a quite different speech act for which these responses are inappropriate.

a. Bobi'=e' u k'áat káa lúub-uk le bak'=o' $\quad$-ki.

Bobby=TOP A3 want for fall-SUBJ DEF meat=DIST - QUOT.B3SG

He goes "Bobby (a dog) wants the meat to fall"

b. \# $\{$ Jaaj // ma' jaaj=i' $\}$

true NEG true=NEG.CL

Intended: 'Yeah.' // 'No.'

One further diagnostic which to my knowledge has not been discussed in previous literature is the ability of the element to occur without any explicit, non-pronominal realization of the original speech event's content/form. Since SAY present the facts of the original speech event as their at-issue content, they have uses in which the 
content/form of the original speech event is either realized pronominally (e.g. He said that, She told me $\emptyset$ ) or is simply not present despite being entailed to exist (e.g. She spoke, He pontificated). Since illocutionary REP, on the other hand, encode the not at-issue status of the original speech event, they are infelicitous in such uses ${ }^{9}$ :

(19) Context: I am talking on the phone with a friend to ask about the weather in our town so we can decide whether to bring umbrellas. You ask me if it's started to sprinkle yet.

*Bin.

REP

Intended: 'He says that.'

Of course, some cases of REP may be infelicitous without their scope content for independent morphological or prosodic reasons (e.g. a REP which is a verbal affix could not occur without the verb). As a clitic, YM bin REP is arguably of this sort. Turning to $k i(j)$ QUOT, we find that it too is infelicitous as seen in (20) (and already observed by Lucy 1993: p. 100), requiring the quoted material to be explicit. Unlike in the case of bin REP, there is no independent reason to expect $k i(j)$ to have such a requirement since $k i(j)$ is prosodically and morphologically independent.
a. Jaan-en $\quad-\mathbf{k i j}-\mathrm{o}^{\prime} \mathrm{ob} \quad\left(\mathrm{ti}{ }^{\prime}\right)$.
eat-IMPER QUOT-B3PL DAT.3SG
“"Eat!" they say (to him).'
b.

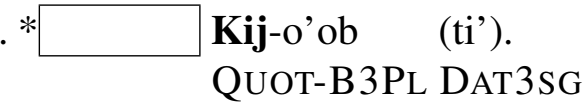
Intended: 'They say it (to him).'

Summing up, we find that QUOT pattern like (illocutionary) REP in that they conventionally mark the original speech event as not-at-issue content.

9 REP which are claimed to contribute to at-issue content in some way at least have the potential to be felicitous in such uses. This possibility is realized for Tagalog daw, which - despite having clearly illocutionary uses (e.g. as discussed by AnderBois (2017)) - has been argued convincingly to contribute to at-issue content in some cases (e.g. Schwager 2010, Kierstead 2015):

(i) Da-rating si John.

FUT-come DIR John

'John is coming.'

Schwager 2010: p. 228

(ii) Daw.

REP

'So they say.' 
At-issueness in direct quotation: the case of Mayan quotatives

\section{Reportatives and quotatives beyond declaratives}

We have just seen that QUOT are similar to REP in marking the original speech event as not-at-issue content. However, we also saw an important difference: the material from the original speech event with QUOT is not readily targeted by unmarked responses. In this section, we look across different sentence types to show that while both are possible across major sentence types, QUOT and REP have quite different illocutionary effects.

Cross-linguistically, REP show a good deal of variability in their grammaticality across sentence types and their interpretation when grammatical. In terms of grammaticality, reportatives appear to obey the following implicational hierarchy:

Reportative implicational hierarchy (tentative): Imperatives $_{R E P}>$ Interrogatives $_{R E P}>$ Declaratives $_{R E P}$

Within Mayan, some languages disallow reportatives outside declaratives (e.g. Q'anjob'al), but most languages allow REP in all three major sentence types (e.g. Haviland 2004 for Tsotsil la, Curiel 2016 for Tojolab'al =b’i). When grammatical, interrogatives with reportatives are known to give rise to some variation across languages, with two main readings widely attested. First, we find what has been called the 'Interrogative flip' interpretation, where the reportative meaning is applied to the expected answer of the addressee (cf. Murray 2017 and references therein). Second, we have what has been dubbed 'Interrogative by proxy' uses in which the reportative meaning is applied to the question itself, in effect passing along the question from the original speaker (cf. Faller 2002: §6.3.2). Note that in both cases, the resulting utterance still typically involves an actual illocutionary question, i.e. one which the addressee is expected to answer. In some languages, both interpretations are possible, as seen with Tagalog daw REP in (22).

(22) Sino daw yung kumanta?

who REP DEM.LNK singer

'Who was the singer?'

Tagalog

a. $\checkmark$ By-proxy context: You went to a concert. My roommate wants to know about the concert and asked me to ask you about it.

b. $\checkmark$ Flip context: Your roommate went to a concert, but I know you didn't. I ask you about the concert with the expectation that you will respond according to what you've been told by your roommate.

In contrast, YM bin - and other Mayan REP as best as can be discerned from attested examples in prior work - only allows the by-proxy interpretation: 
AnderBois

Uts-chaj wáaj bin le cha'an=o'

good-PROC INTERR REP DEF spectacle=DIST

'Was the concert good?'

a. $\checkmark$ By-proxy context: You went to a concert. My roommate wants to know about the concert and asked me to ask you about it.

b. \# Flip context: Your roommate went to a concert, but I know you didn't. I ask you about the concert with the expectation that you will respond according to what you've been told by your roommate.

Turning to imperatives with REP, when they are grammatical, they appear from what little is known to be cross-linguistically uniform in interpretation. Imperatives with reportatives serve the same range of illocutionary functions as other imperatives, as seen in (24a-24b) for YM bin (cf. AnderBois (2017) for detailed discussion and parallel data from Tagalog daw).

(24) a. Order Scenario: Our mother has told me to make sure that my younger sibling eats their dinner. After talking to her, I tell my sibling:

Uk' bin a wo'och k'eyem=o'

drink.IMPER REP A2 meal pozole=DIST

'Drink your pozole (she orders)!'

b. Offer Scenario: A child's mother has told them they should offer cake to guests. The child says to a guest:

Jaant bin le paastel=a'

eat.IMPER REP DEF cake $=$ DIST

'Eat this cake (Mom told me to offer it)!

Summarizing across the three major sentence types, YM bin REP does not alter the basic illocutionary update associated with the sentence type. Returning to QUOT, the situation we find is quite different. While QUOT are compatible with all three major sentence types, the resultant utterances do not have the characteristic illocutionary update otherwise associated with each sentence type. Rather, we find that across all three major illocutionary moods, sentences with QUOT uniformly produce a speech act of 'dialogue narration'. While another character within the narrative universe may respond to the characteristic illocutionary effect of the sentence (e.g. providing an answer in the case of an interrogative), it is infelicitous for the actual addressee to respond in these ways. We have seen this above for declaratives in (18a) and illustrate it here for interrogatives and imperatives:

(25) Interrogative

a. -Hijo,- $\boldsymbol{k}$-en ti', -buka'aj le tikin muuk a meentmaj-e'ex=o'?

son QUOT-B1SG DAT.3SG how.many DEF dry seed A2 do-A2PL=DIST

" "Son," I said to him, "how many dry plantings did you do?", 
At-issueness in direct quotation: the case of Mayan quotatives

b. To'on=e'-, $\boldsymbol{k} \boldsymbol{i}, \quad$-casi veinte yaale'. we $=$ TOP QUOT.BS3G almost twenty??

" "Us", he said, "almost 20 units of land". , Narraciones mayas, p. 275

(26) Imperative

a. Ok-en ka kan le k'aay k-in meentik=a' $-\boldsymbol{k i} \underline{\text { bin }}$. enter-IMPER for read DEF song IPFV-A1 make=PROX -QUOT REP 'Come in to learn the song we're making!'

b. Ka jo'op' u k'aay xan. for begin A3 sing too

'She began to sing'

Maayáaj ts'ikbalilo'ob kaampech, p. 23

\section{A scoreboard account of quotatives}

We have seen above that despite introducing direct verbatim quotes, QUOT nonetheless share with REP that they conventionally encode the existence and properties of the original speech event as not-at-issue content. This is a counterintuitive state of affairs from the point of view of the literature on quotation and also the literature on at-issueness.

For quotation, arguably the central focus of previous accounts is precisely to take something quite unlike ordinary, at-issue propositional content - the linguistic form being quoted - and find compositional ways to nonetheless allow it to contribute to propositional content. That said, many of most challenging cases traditionally considered such as mixed quotation, partial quotation, and pure quotation do not arise for Mayan QUOT. Instead, Mayan QUOT are used almost exclusively for quoting stretches of dialogue in narrative discourse.

For at-issueness, we typically think of not-at-issue content as contributing 'side notes' to at-issue content. If the facts about the original speech event itself are not-at-issue as we have claimed, what, then, is the at-issue content in these cases? The linguistic material being quoted would seem to be the only candidate, and yet it's not clear how linguistic material could possibly be at-issue content. That said, we can again note the unique nature of Mayan QUOT and in particular the fact that their use is limited to narration. A speaker's primary purpose in telling a story is plausibly not to figure out what the actual world is like (i.e. to answer Roberts (1996)'s "Big question"), but rather to provide a characterization of some other reality, that of the narrative.

In this section, we briefly sketch an account of Mayan QUOT which makes use of this intuition to capture the core facts about QUOT within a Farkas \& Bruce (2010)-style 'scoreboard' model of discourse. In §6.1, we review AnderBois (2014, 2017)'s scoreboard account of REP. In $§ 6.2$, we extend the account to QUOT, arguing 
that QUOT conventionally encode that the speaker is recreating or demonstrating an update to an in-narrative scoreboard.

\subsection{REP in the scoreboard}

Following AnderBois $(2017,2018)$, we take a discourse context $\mathscr{C}$ to consist of a tuple $\left\langle\mathbf{I}, \mathbf{S}\right.$, Table, $\left.\mathbf{D C}_{x}\right\rangle$. I is the set of individuals who are participants in the discourse, for the sake of simplicity, we take I to contain only two individuals, $a$ and $b . \mathbf{S}$ is the joint action state of the discourse, consisting of information, preferences, etc. that are shared among discourse participants and serve as the basis for planning their joint goals and actions, both conversationally and domain goals beyond the conversation. We take $\mathbf{S}$ to be comprised of three elements: the Common Ground $\mathbf{C G}_{\{a, b\}}$, Questions Under Discussion QUD $\mathbf{D}_{\{a, b\}}$, and Common Effective Preferences CPref $\mathbf{P}_{\{a, b\}} \cdot \mathbf{C G}_{\{a, b\}}$ and QUD $\mathbf{D}_{\{a, b\}}$ are Roberts and Stalnaker's familiar notions, while CPref $\{a, b\}$ is the shared effective preference structure of $a$ and $b$ (see Condoravdi \& Lauer $(2012,2016)$ for the notion of effective preferences). ${ }^{10}$. The Table represents proposals to update components of $\mathbf{S}$ subject to negotiation by the discourse participants in $\mathbf{I}$ and governed by constitutive rules laid out in Farkas \& Bruce (2010) (as well as normative constraints regarding how such proposals relate to $\mathbf{S}$ ). Finally, we have for each individual $x \in \mathbf{I}, \mathbf{D C}_{x}$ the set of propositions $p$ such that $x$ is publicly committed to believe $p$.

The three basic sentence types, then, place on the Table proposals to update the various components of $\mathbf{S}: \mathbf{C G}_{\{a, b\}}$ for declaratives, $\mathbf{Q U D}\{a, b\}$ for interrogatives, CPref $_{\{a, b\}}$ for imperatives. One key claim of Farkas \& Bruce (2010) is that the conventional effect of declaratives includes updates to both the individual $\mathrm{DC}_{a}$ and a proposal to update $\mathbf{C} \mathbf{G}_{\{a, b\}}$. While imperative and interrogative sentences might invite inferences about the speaker's personal goals and preferences, we follow AnderBois (2018) in these to not be part of the conventional effect of these sentence types, unlike in the case of declaratives.

a. Context: Alfredo is talking to Beatriz It's raining.

b. Scoreboard update for (27a):

\begin{tabular}{|c|c|c|c|}
\hline $\mathbf{a}$ & & $\mathscr{C}$ & $\mathbf{b}$ \\
\hline $\mathbf{D C}_{a}$ & $p$ & Table $_{\{a, b\}}$ & $\mathbf{D C}_{b}$ \\
\hline $\mathbf{C} \mathbf{G}_{\{a, b\}}$ & & $\mathbf{Q U D}_{\{a, b\}}$ & $\operatorname{CPref}_{\{a, b\}}$ \\
\hline
\end{tabular}

10 The idea that imperatives contribute proposals to update something like shared effective preferences has developed in a variety of recent works such as Starr (2013), von Fintel \& Iatridou (2017), AnderBois (2017), AnderBois (2018), and Rudin (2018). 
At-issueness in direct quotation: the case of Mayan quotatives

One important departure from many prior scoreboard models is that we take both $\mathbf{C G}_{\{a, b\}}$ and $\mathbf{D C}$ to be primitives, rather than being interdefinable as they are in works such as Gunlogson (2001) and Farkas \& Bruce (2010). Whereas Stalnaker (1978) famously defines $\mathbf{C G}_{\{a, b\}}$ as the set of propositions that a given set of conversational participants $\{a, b\}$ is publicly committed to acting as though are true, $\mathbf{D C}_{x}$ concerns public commitments to actual beliefs, with no caveat for "acting as though". ${ }^{11}$

AnderBois $(2014,2017)$ makes use of the disconnect between these two in order to analyze REP such as YM bin REP as creating 'asymmetric' updates where $\mathrm{DC}_{a}$ and $a$ 's proposal do not match in content. Specifically, REP modifies the update the speaker makes to $\mathrm{DC}_{x}$ while leaving the proposal placed on the Table unmodified, as in (28b). For a declarative like (28a), then, the effect is one of face-saving: $a$ tries to steer I towards acting jointly as though $p$, while avoiding staking their epistemic reputation on the truth of $p$ through disclosing their reasons for proposing to act as though $p$ more explicitly.

(28) a. Scenario: I am talking on the phone with a friend to ask about the weather in our town so we can decide whether to bring umbrellas and I tell you:

Táantik bin u chuunul u toosol ja'=e'

IMM.PAST REP A3 start A3 sprinkle water=TOP

'It just started to sprinkle (he says).'

b. Scoreboard update for (28a):

\begin{tabular}{|c|c|c|c|c|}
\hline $\mathbf{a}$ & & & & $\mathbf{b}$ \\
\hline $\mathbf{D C}_{a}$ & $\operatorname{REP}(p)$ & Table $_{\{a, b\}}$ & $p$ & $\mathbf{D C}_{b}$ \\
\hline $\mathbf{C} \mathbf{G}_{\{a, b\}}$ & & $\mathbf{Q U D}_{\{a, b\}}$ & & $\operatorname{CPref}_{\{a, b\}}$ \\
\hline
\end{tabular}

where $p$ is the proposition that it is raining (at the time/location of utterance)

There are two important aspects of the proposal to note in the current context. First, in terms of the illocutionary update associated with the sentence, sentences with REP place the same proposal on the Table as those with no REP. This prediction is correct in that as we have seen above (and in more detail in the works cited), sentences with Mayan REP can be used to perform the same range of speech acts as corresponding sentences with no REP. Second, in terms of at-issueness, the account captures the observation that the facts concerning original speech act are not-at-issue content. As Farkas \& Bruce (2010) highlight in their account of unmarked responses like 'yes' and 'no', at-issueness concerns the content placed on the table. At the same time, Farkas \& Bruce (2010) formalize the Table as being a special sort of QUD, thus allowing for an account of the connections between QUDs and at-issueness.

11 From the prose in these prior works, it is not entirely clear how different the conceptual definitions of $\mathbf{D C}_{x}$ and $\mathbf{C} \mathbf{G}_{\{a, b\}}$ really are. Nonetheless, we regard the decision to take $\mathbf{C} \mathbf{G}_{\{a, b\}}$ to be equivalent to $\bigcap_{x \in \mathbf{I}} \mathrm{DC}_{x}$ as incompatible with the view here. 
AnderBois

\subsection{QUOT in the scoreboard}

Whereas REP in Mayan languages still are used to make the same range of illocutionary updates as sentences with no reported speech elements, we have argued that QUOT uniformly are used to perform speech acts of dialogue narration, one where facts about the original act are not at-issue. The intuition we pursue here is the scope material with Mayan quotatives interacts with a discourse scoreboard just like any matrix utterance would, it just does so within the universe of the narrative. That is to say, what we need in order to capture Mayan quotatives are 'ad-hoc' scoreboards inside of narrative universes which quotative utterances update. Narration, whether of fiction or of non-fiction, is akin to building a separate conversational reality, and narrating dialogue is a special case of this. The original speech material with QUOT should therefore behave as ordinary at-issue content within the narrative scoreboard rather than the actual scoreboard. We illustrate this for (29a) in (29b):

(29) a. Context: Venustiano is telling a true story to a researcher, César. He introduces a character in the story, Don Miro, a one hundred year-old man who is talking to his children, including Salvador. The story then continues with his children responding and some further back and forth.

Ten=e', paal-e'ex, ten=e' ma' j-oken ti' esclavitud=i' -ki I=TOP child-B2PL I=TOP NEG PFV-enter PREP slavery=NEG.CL QUOT

' "I, children, I wasn't a slave." he said.' Can Canul \& Gutiérrez-Bravo (2016: p. 136)

\begin{tabular}{|c|c|c|}
\hline $\mathbf{v}$ & $\mathscr{C}_{\text {Actual }}$ & c \\
\hline $\mathbf{D C}_{v} \quad(\operatorname{say}(m, p))$ & Table $_{\{v, c\}}$ & $\mathbf{D C}_{c}$ \\
\hline $\mathbf{C} \mathbf{G}_{\{m, s\}}$ & $\mathbf{Q U D}_{\{m, s\}}$ & $\operatorname{CPref}_{\{m, s\}}$ \\
\hline
\end{tabular}

\begin{tabular}{|c|c|c|c|c|}
\hline $\mathbf{m}$ & & $\mathscr{C}_{\mathrm{Na}}$ & & $\mathbf{S}$ \\
\hline $\mathbf{D C}_{m}$ & $p$ & Table $_{\{m, s\}}$ & $p$ & $\mathbf{D C}_{S}$ \\
\hline $\mathbf{C G}_{\{m, s\}}$ & & $\mathbf{Q U D}_{\{m, s\}}$ & & $\operatorname{CPref}_{\{m, s\}}$ \\
\hline
\end{tabular}

where $p$ is the proposition that Don Miro was not a slave

In terms of the illocutionary update associated with QUOT, then, we see that effect on the actual conversational scoreboard is common to all sentence types: to add the information regarding what the original speaker said to $\mathrm{DC}_{v} \cdot{ }^{12}$ Different sentence types give rise to different effects within the narrative scoreboard, of course, but unlike with REP, these differences are not felt in the actual scoreboard. In terms

12 Even this we might reasonably consider to be more akin to Stalnaker's goat than truly being part of the conventionally encoded update. That is to say, the fact that the speaker demonstrated an utterance within the narrative may often indicate the speaker's belief that the individual did say this, but this may not be part of their communicative intent per se. 
of at-issueness, we see that like REP, there is no proposal put on the Table in $\mathscr{C}_{\text {Actual }}$ (or indeed on any Table) which includes information about the original speech event.

QUOT, then, serve two functions. First, they make explicit (often redundantly) that the adjacent material is to be interpreted relative to an in-narrative scoreboard rather than the actual one. Second, in so doing, they enough basic elements of the conversational context within the narrative universe to help the audience figure out where in the narrative universe they are located and who is talking to who within that setting. While it's unclear whether quotative elements in other languages consistently show a similar restriction, we can note that the elements encoded by the QUOT - speaker and addressee - are those which play privileged roles in the scoreboard model, whereas other things common to ordinary verbal clauses such as time, location, manner, etc. are not. The basic intuition is that dialogue in narrative whether fictional or real - involves displacing ourselves to some other point in time, space, perspective, etc. Once at those alternative coordinates, agents in the narrative can make moves like in any other conversation, moves which locally interact with one another in normal ways (cf. Eckardt (2015) for a proposal for Free Indirect Discourse in a broadly similar vein).

One question which arises at this point, then, is what the purpose of narratives of this sort are if they do not serve to update the shared scoreboard elements of the actual conversational scoreboard. One response could be to simply to relax the normal assumption that enriching the $\mathrm{CG}$ (or CPref) is the purpose of conversation. That is to say, we might consider narrative as representing a genre in which this goal simply is not relevant. While this may well be true of some narratives, in other cases, it would seem that simply abandoning this assumption is less plausible. Consider, for instance the case of a politician on the campaign trail. Clearly, there is a very salient actual issue the candidate aims to address: who is the best candidate to vote for? And yet, the politician often will aim to settle this issue not by providing facts about themself or their opponents, but rather by telling a narrative about the steel mill worker or single mother they met out on the campaign trail. Such narratives do not directly update the discourse scoreboard and yet, clearly this is often an effective strategy of producing such a change despite this indirectness.

We assume therefore that updates to an in-narrative scoreboard may ultimately impact the state of the actual conversation, but do so in a way that is far less direct. Without a theory of narrative thought, we cannot say more than this, but hope that it's clear that we should not be troubled by the fact that narrative may fail to make any at-issue contribution in some sense. What is notable, however, is that Mayan quotatives present a rare case where the use of this narrative mode is conventionally encoded by grammar. 
AnderBois

\section{Conclusions}

In this paper, I have investigated the behavior in discourse of Mayan quotatives, focusing on Yucatec Maya $k i(j)$ QUOT. While quotatives have often been regarded as special kinds of reportative evidentials or verbs of saying, I have argued that they show important differences (and similarities) with both of these elements, summarized in (30):

\section{(30) Properties of Quotatives, Reportatives, and Verbs of Saying:}

$\begin{array}{llll} & \text { REP } & \text { SAY } & \text { QUOT } \\ \text { Indirect speech use? } & \text { Yes } & \text { Yes } & \text { No } \\ \text { Direct speech use? } & \text { No } & \text { Yes } & \text { Yes } \\ \text { Original speech event not A-I } & \text { Often conventional } & \text { Pragmatic } & \text { Conventional } \\ \text { Interaction with sentence type } & \text { Variable, complex } & \text { Narrow scope } & \text { Wide scope } \\ \text { Details of original speech event } & \text { Implicit } & \text { Explicit } & \text { Limited }\end{array}$

In order to account for this set of properties, I have proposed a scoreboard semantics for QUOT in which they demonstrate an ordinary update to an in-narrative context, providing limited not-at-issue information about the original speech event. Just as REP provide a distinct 'mode' of presenting indirect speech reports, Mayan QUOT do the same for direct speech reports.

We close by returning to an outstanding puzzle noted in passing in $\S 2$. There we saw that, despite the differences we have noted between QUOT and REP, the two morphemes can and frequently do co-occur. When bin REP occurs inside of the quoted material that $k i(j)$ introduces, things are as expected and this merely quotes an original speech event which happens to contain REP. However, when the reverse situation obtains and REP occur outside of the quoted material, we unexpectedly find a 'reportative concord' use which appears to have the same meaning as a corresponding sentence without bin REP, (5). Beyond this, AnderBois (2019) shows that examples which also contain SAY can behave similarly, as in (31).

$$
\begin{aligned}
& \text { K-u y-a'al-ik bin=e': ma' táan }-\boldsymbol{k i} \quad \frac{b i n}{R} \\
& \text { IPFV-A3 EP-say-SS REP=TOP NEG PROG QUOT REP }
\end{aligned}
$$
'he responded: no - he said.' (Can Canul \& Gutiérrez-Bravo 2016: 22)

We leave it to future work to analyze such cases, but note that various sorts of similar such concord uses for REP appear to be cross-linguistically quite common, a pattern that highlights the fact that despite the various differences between different elements we have seen, REP, QUOT, and SAY nonetheless have a shared core that goes above and beyond their propositional content. 
At-issueness in direct quotation: the case of Mayan quotatives

\section{References}

AnderBois, Scott. 2014. On the exceptional status of reportative evidentials. In Semantics and Linguistic Theory (SALT) 24, 234-254.

AnderBois, Scott. 2016. Semantics and pragmatics of (not-)at-issueness in Yucatec Maya attitude reports. Semantics \& Pragmatics 9(19).

AnderBois, Scott. 2017. An illocutionary account of reportative evidentials in imperatives. Semantics and Linguistic Theory (SALT) 27 459-479.

AnderBois, Scott. 2018. Illocutionary revelations: Yucatec Maya bakáan and the typology of miratives. Journal of Semantics 35(1). 171-206. doi:doi.org/10.1093/jos/ffx019.

AnderBois, Scott. 2019. Reportatives and quotatives in Mayan languages. In Proceedings of Form and Analysis in Mayan Linguistics (FAMLi) 5, .

Bary, Corien \& Emar Maier. 2018. The landscape of speech reporting. Unpublished Manuscript, downloaded from second author's website 11/27/2018.

Blain, Eleanor M. \& Rose-Marie Déchaine. 2007. Evidential types: Evidence from Cree dialects. International Journal of American Linguistics 73(3). 257-291.

Bohnemeyer, Jurgen. 2002. The grammar of time reference in Yukatek Maya. LINCOM: Europa.

Can Canul, Cesar \& Rodrigo Gutiérrez-Bravo. 2016. Maayáaj tsikbalilo’ob kaampech. INALI.

Condoravdi, Cleo \& Sven Lauer. 2012. Imperatives: meaning and illocutionary force. In Empirical issues in syntax and semantics 9, 37-58.

Condoravdi, Cleo \& Sven Lauer. 2016. Anankastic conditionals are just conditionals. Semantics \& Pragmatics 8. 1-69. doi:10.3765/sp.9.8.

Curiel, Alejandro. 2016. Estructura narrativa y evidencialidad en tojolabal: Universidad Nacional Autónoma de México (UNAM) PhD dissertation.

Eckardt, Regine. 2015. The semantics of free indirect discourse. Brill Publishing.

Faller, Martina. 2002. Semantics and pragmatics of evidentials in Cuzco Quechua: Stanford $\mathrm{PhD}$ dissertation.

Faller, Martina. 2006. Evidentiality below and above speech acts. Ms. University of Manchester, online at:

http://semanticsarchive.net/Archive/GZiZjBhO/

Faller-evidentiality.above.below.pdf.

Farkas, Donka \& Kim Bruce. 2010. On reacting to assertions and polar questions. Journal of Semantics 27(1). 81-118.

von Fintel, Kai \& Sabine Iatridou. 2017. A modest proposal for the meaning of imperatives, 288-319. Oxford University Press.

Gunlogson, Christine. 2001. True to form: Rising and falling declaratives as questions in English: University of California, Santa Cruz PhD dissertation. 
Haviland, John. 2004. Evidential mastery. In Proceedings of CLS 38-2, The Panels, 349-368.

Hull, Kerry. 2003. Verbal art and performance in Ch'orti' and Maya hieroglyphic writing: University of Texas Austin $\mathrm{PhD}$ dissertation.

Hunter, Julie. 2016. Reports in discourse. Dialogue \& Discourse 7(4). 1-35.

Jayaseelan, K.A. \& R. Amritavalli. 2017. Dravidian syntax and universal grammar. Oxford University Press.

Kierstead, Gregory. 2015. Projectivity and the Tagalog reportative evidential: The Ohio State University MA thesis.

Korta, Kepa \& Larraitz Zubeldia. 2014. The contribution of evidentials to utterance content: evidence from the Basque reportative particle omen. Language 90(2). 389-423.

Krawczyk, Elizabeth. 2012. Inferred propositions and the expression of the evidence relation in natural language: Evidentiality in Central Alaskan Yupik Eskimo and English: Georgetown PhD dissertation.

López Jiménez, José Alfredo. 2010. Estructura, actuación y multimodalidad en la narrativa personal oral (lo'il a'yej) de la comunidad tsotsil de romerillo, chamula, chiapas: Centro de Investigación y Estudios Superiores en Antropología Social (CIESAS), México MA thesis.

Lucy, John. 1993. Metapragmatic presentationals: Reporting speech with quotatives in Yucatec Maya. In John Lucy (ed.), Reflexive language: reported speech and metapragmatics, 91-125. Cambridge University Press.

Maier, Emar. 2009. Japanese reported speech: against a direct-indirect distinction. In Hiromitsu Hattori, Takahiro Kawamura, Tsuyoshi Idé, Makoto Yokoo \& Yohei Murakami (eds.), New frontiers in artificial intelligence (lecture notes in computer science 5447), 133-145. Springer.

Maier, Emar. t.a. Mixed quotation. In The companion to semantics, Wiley Blackwell. Matthewson, Lisa, Henry Davis \& Hotze Rullmann. 2007. Evidentials as epistemic modals: evidence from St'átimcets. Linguistic Variation Yearbook 7. 201-254.

Murray, Sarah. 2010. Evidentiality and the structure of speech acts: Rutgers $\mathrm{PhD}$ dissertation.

Murray, Sarah. 2014. Varieties of update. Semantics \& Pragmatics 7(2). 1-53.

Murray, Sarah. 2017. The semantics of evidentials. Oxford University Press.

Roberts, Craige. 1996. Information structure in discourse. In OSU Working Papers in Linguistics, Revised 1998 version, retrieved from author's webpage 8/20/09.

Rudin, Deniz. 2018. Rising imperatives. In Semantics and Linguistic Theory (SALT) $28,100-119$.

Schwager, Magdalena. 2010. On what has been said in Tagalog. In Evidence from evidentials, 221-246. University of British Columbia Working Papers in Linguistics. 
At-issueness in direct quotation: the case of Mayan quotatives

Simons, Mandy. 2007. Observations on embedding verbs, evidentiality, and presupposition. Lingua 117. 1034-1056.

Stalnaker, Robert. 1978. Assertion. In Syntax and semantics 9, .

Starr, William. 2013. A preference semantics for imperatives. Ms. Cornell University.

Scott AnderBois

Brown University

Box 1821

190 Thayer St.

Providence, RI 02912

scott_anderbois@brown.edu 